\title{
La novela popular y 2666 (2004) de Roberto Bolaño
}

\author{
Carmen FRAGERO GUERRA \\ EUMI “Sagrado Corazón”-Universidad de Córdoba
}

\section{RESUMEN}

En estas líneas se demuestra que "De la parte de Archimboldi", un capítulo de 2666 (2004) de Roberto Bolaño (1947-2000), se puede unir con la corriente de novelas populares de corte realista que comenzó en la segunda mitad del siglo XIX. La novela posmoderna une en sí elementos populares y elementos pertenecientes a una cultura minoritaria, pero hace falta analizar ejemplos concretos de obras recientes que lo confirmen. Al encontrar los elementos populares que distinguen a 2666 (2004), contribuimos a estudiar la novela hispanoamericana actual siguiendo los pasos de investigadores como Vance R. Holloway y Gonzalo Navajas. El texto muestra cómo Roberto Bolaño toma rasgos de la novela popular pero utiliza sus códigos narrativos de un modo irónico y nuevo.

Palabras clave: Bolaño, Archimboldi, códigos narrativos.

\section{The popular novel and 2666 (2004) by Roberto Bolaño}

\begin{abstract}
In these lines it is demonstrated that "De la parte de Archimboldi", a chapter of 2666 (2004) by Roberto Bolaño (1947-2000), can be linked to a series of Spanish realistic popular novels that began in the second half of the 19th century. It is said that the postmodern novel has adopted the popular and the cultural streams although no definite examples of current novels have been studied. On discovering the popular features which distinguish 2666 (2004), we analyse the contemporary Hispano-American novel, following the paths of authors such as Vance R. Holloway and Gonzalo Navajas. The text shows how Roberto Bolaño takes advantage of the features of the popular novel but uses its narrative codes in an ironic and new manner.
\end{abstract}

Keywords: Bolaño, 2666, Archimboldi, Narrative codes.

Sumario: 1. Introducción. 2. Interés por la acción: historias dentro de la historia novelesca. 3. Novela realista de historia contemporánea. 4. Introducción de personajes: vida pasada. 5. Presencia del autor. 6. Narrador omnisciente. 7. Cambios de perspectiva en la narración. 8. Anticipación o prolepsis. 9. Simbología. 10. Conclusión. 


\section{Introducción}

En este trabajo se estudia la novela póstuma 2666 (2004) del autor chileno Roberto Bolaño (1947-2000). Las directrices de la novela contemporánea hispanoamericana son variadas y la falta de perspectiva histórica dificulta la selección de las obras más significativas para su análisis. Al buscar los rasgos comunes de 2666 (2004) de Roberto Bolaño y la novela de folletín, contribuimos a caracterizar la novela contemporánea en la línea de estudios realizados por autores como Gonzalo Navajas, en los que se intenta buscar los rasgos peculiares de la novela actual (1996: 22-23). El posmodernismo se caracteriza por una fusión de la cultura popular y la restringida a públicos minoritarios. Así, Vance R. Holloway afirma que una de las características de la novela posmoderna es "un hibridismo genérico basado en un síntesis narrativa del folletín, de la novela rosa y de la novela detectivesca" (1999: 109).

El marco teórico en el que nos basamos proviene de mis anteriores estudios sobre la novela romántica y de trabajos de autores especializados, que serán citados oportunamente (Fragero, 1989, 1997, 2000). El método que llevaremos a cabo será constatar, con la autoridad de estudiosos del tema, las características propias de la novela post- romántica y ver cómo éstas también aparecen en la novela que estudiamos, 2666 (2004) de Roberto Bolaño. De igual modo, buscaremos ejemplos concretos en la novela de folletín de El Patriarca de Valle (1846-1847) de Patricio de la Escosura que corroboran nuestra intuición.

La novela romántica se puede dividir en tres fases: el prerromanticismo (de los años 1827 a 1833), el romanticismo (de los años 1834 a 1844) y el postromanticismo (de 1845 a más allá de 1850) (Brown, 1953: 26). El Patriarca de Valle (1846-1847) de Patricio de la Escosura se encuadra en la tercera fase; es un híbrido entre la influencia francesa, representada por el Judio Errante (1844-1845) de Eugène Sue, y la corriente de la novela realista española, iniciada en el primer romanticismo. El Patriarca de Valle (1846-1847) de Patricio de la Escosura es una novela de folletín que ha llegado a nosotros encuadernada. En ella se puede apreciar las características de la novela popular. Esta, según Leonardo Romero Tobar, es "toda la producción narrativa anterior a 1870" que se presenta como "un bloque homogéneo en el que los rasgos de creación individual escasamente sirven para anular la impresión de uniformidad, de estructuras repetidas, que se reiteran de modo infatigable" (Romero Tobar, 1976: 119). Este autor intenta aislar estas estructuras o códigos repetidos en un corpus de novelas que se extiende de 1831 a 1867 (Romero Tobar, 1976: 124-150). Nosotros, basándonos en su estudio y en los códigos populares encontrados en El Patriarca del Valle (1846-47) de Patricio la Escosura (Fragero, 1989: 121-140), buscaremos esos mismos códigos en la novela 2666 (2004) de Roberto Bolaño

2666 (2004) de Roberto Bolaño consta de cinco partes o capítulos: "La parte de los críticos", "La parte de Amalfitano", "La parte de Fate" y "La parte de Archim- 
boldi"1. Estos capítulos, concebidos por el autor como libros independientes, fueron finalmente editados en un solo volumen. Debido a la gran extensión de esta novela, 1125 páginas, hemos centrado nuestro estudio en "La parte de Archimboldi” (Bolaño, 2005: 793-1121). Esta última presenta una estructura más folletinesca: por la complicación de su trama, la gran cantidad de digresiones y las numerosas historias secundarias dentro de la historia principal.

Ya ha sido estudiada la adhesión de autores contemporáneos, como por ejemplo Isabel Allende -con su saga de novelas como La Hija de la Fortuna (1999) y Retrato en Sepia (2000)-, a la corriente de la novela popular en su sentido más puro. Esta autora sigue las pautas de la novela popular fielmente, como ha demostrado Federico Pastene Labrín (2004: 119). En sus novelas encontramos: una fuerte heroína que busca al amado, una estructura serial, la clave erótica con fin didáctico, la publicación vinculada a periódicos y la correspondencia de los lectores con la autora -en este caso por medio de sus página $\mathrm{Web}-$, entre otros rasgos folletinescos. La aportación de la autora chilena es un eslabón más en la corriente de novelas populares. Por el contrario, Roberto Bolaño toma sólo algunos códigos de éstas pero, al ser utilizados inversamente, son más significativos.

El autor se rinde simuladamente ante un tipo de novelas, "los folletones" que "se venden y gozan del favor del público porque sus historias se entienden" (Bolaño, 2009: 162). Pero su ingenio le lleva a servirse del medio con otro fin; se vale de unas estructuras en las que el lector se siente cómodo para incomodar al lector por el uso invertido de las mismas. Respecto a este género, nos dice irónicamente:

En el folletón está la salvación del lector (y de paso, de la industria editorial). Quién nos lo iba a decir. Mucho presumir de Proust, mucho estudiar las páginas de Joyce que cuelgan de un alambre, y la respuesta está en el folletón. Ay, el folletón. [...] Todo lleva a pensar que esto no tiene salida (Bolaño, 2009: 177) [Énfasis añadido].

A continuación, enumeramos algunas características propias de la novela de folletín de la segunda mitad del siglo XIX que aparecen, con matices distintos, por contener más nivel intelectual, en "La parte de Archimboldi" de 2666 (2004) de Roberto Bolaño.

${ }^{1}$ Cuando nos referimos a la novela de Roberto Bolaño, 2666 (2004) incluimos entre paréntesis la fecha de la primera edición, 2004, pero al citar los textos concretos, damos la fecha de la quita edición, 2005, que es la utilizada en este trabajo y citada en las referencias bibliográficas. 


\section{Interés por la acción: historias dentro de la historia novelesca}

El interés por la acción en detrimento de la caracterización de los personajes es un recurso típico de la novela de folletín y alcanza en "La parte de Archimboldi" su grado máximo. Romero Tobar ha analizado las novelas populares españolas anteriores a Galdós y concluye que, en ellas, existe un interés por las acciones de los personajes, más que por la evolución de sus caracteres:

Al novelista le interesa en primer lugar la acción y, en un segundo plano muy disminuido, las caracterizaciones tipológicas; de los personajes sólo entrega la filiación y las señas exteriores de identidad, no su hacerse o deshacerse vital (1976: 124).

En "La parte de Archimboldi", miles de historias, unas dentro de otras, nos dan la visión de una realidad multifacética y complicada. Aparecen historias desestructuradas que no tienen relevancia en la historia posterior. Por ejemplo: la historia de Vogel, el turista altruista que evitó que Reiter se ahogara (Bolaño, 2005: 805); o se dan rasgos de personajes que no se vuelven a tocar en otros episodios, como por ejemplo de Hugo Halder, el sobrino del barón, del que se dice que está enamorado de la baronesa Von Zumpem, hija del barón Von Zumpe (Bolaño, 2000: 816).

Según Alfonso Sánchez Rey, conviven dos tipos de relatos: por una parte existe, "un relato de acontecimientos" cuya función es contar en sentido estricto y en el que los hechos son presentados al lector de una forma distante y lejana y, por otra parte, "un relato de palabras" donde la distancia es prácticamente inexistente y se presenta a los personajes hablando por sí mismos. Este relato de palabras es cercano al drama, "su función, por tanto, no es en sentido estricto contar, sino la de servir de expresión a las distintas hablas ajenas a la voz del narrador" (1991: 103-104). Bolaño utiliza ambos métodos pero se inclina más por el primero, dando lugar a una narración densa, complicada en su argumento y muy difícil de resumir, porque la narración ya está en sí misma resumida. A continuación, se exponen unos ejemplos que muestran la elección por parte del narrador de un relato de acontecimientos:

\section{Ejemplo 1: Historia de Ansky}

El soldado alemán Reiter encuentra el diario del judío Ansky. Entre sus muchas aventuras, se narra su actividad en la Rusia contemporánea a la Segunda Guerra Mundial. Este recurso le sirve al autor para presentarnos una sociedad dictatorial y corrompida en la que Ansky llega a ser miembro del partido comunista. La narración de la vida de Ansky toma fundamentalmente una modalidad denotativa, "donde lo fundamental sería la información exenta de cualquier consideración" (Sánchez Rey, 1991: 114), aunque, también, es híbrida entre un Curriculum Vitae y un informe de un espía. 
Fue miembro fundador del Teatro de las Voces Imaginarias. Intentó que alguna editorial publicara unos escritos póstumos de Khlebnikov. Entrevistó como periodista de un periódico que jamás vio la luz a los generales Tjacjevki y Blucher. Tuvo una amante, la doctora en medicina María Zamiatina, diez años mayor que él y casada con un alto dirigente del partido. Hizo amistad con Grigori Yakovin, gran conocedor de historia contemporánea alemana, con quien mantuvo largas conversaciones callejeras sobre la lengua alemana y el yiddish (Bolaño, 2005: 895-896).

Khlebnikov fue fundador del movimiento futurista y, más tarde, murió en las purgas estalinistas. De este modo, Roberto Bolaño inmortaliza en su novela a personajes que, aunque fueron autores menores, contribuyeron a crear las letras contemporáneas.

\section{Ejemplo 2: La historia de Ivanov}

Reiter, el soldado alemán, encuentra un diario de un judío alemán, Ansky. Entre las diversas historias narradas en este diario, tenemos la del escritor ruso Ivanov. Este será primero alabado por el régimen comunista y, luego, criticado hasta ser encarcelado y asesinado durante la época estalinista (Bolaño, 2005: 888-910). La historia del escritor ruso es tan pormenorizada que, incluso, se narra con detalle el argumento de su novela El ocaso así como el de sus obras siguientes -que no gustaron a la crítica comunista por tratar temas de ciencia ficción-. Finalmente, se narra el asesinato de Ivanov en las cárceles rusas. Dentro de esta historia, tenemos la de la joven comunista Nadja, que expulsa al escritor Ivanov del entierro de Gorki. Nadja es el prototipo de la joven revolucionaria rusa y sin prejuicios. Los personajes se caracterizan por acciones; Nadja va a la universidad donde oye a jóvenes poetas, hace el amor impetuosamente con Ansky una noche y desaparece a la mañana siguiente. Así la transformación de la Rusia comunista aparece ejemplificada en la historia particular de Nadja y del escritor Ivanov.

\section{Novela realista de historia contemporánea}

Esta característica también es heredada de toda una corriente de novelas históricas costumbristas que comienzan en la segunda mitad del siglo XIX. Así, por ejemplo, en la novela de folletín El Patriarca del Valle (1846-1847) la historia novelesca y la gran Historia, el reinado de Fernado VII, están entrelazadas. Lo mismo ocurre en las primeras novelas de Galdós, consideradas por Romero Tobar como novelas populares. En éstas vemos también cómo "los personajes y hechos históricos son aludidos y evocados, mientras que los que ocupan el entramado estructural de la novela son resultados de la actividad fabuladora del novelista" (1976: 175). 
En "La parte de Archimboldi", los personajes novelescos participan de estos sucesos y su devenir en la historia novelesca se ve condicionada por la gran Historia: Reiter, soldado alemán, está en un campo de concentración y lucha en las filas de Hitler. Se cambia el nombre de Reiter a Archimboldi para ocultarse porque había matado a Stammer, jefe nazi que asesinó a muchos judíos en Polonia. También el escritor Ivanov, personaje novelesco, va al entierro de Gorki, personaje histórico. La historia novelesca de Ivanov se entrecruza así con los personajes de la gran Historia, lo que contribuye a dar verosimilitud al relato. Las referencias a personajes históricos menores, fundamentalmente literatos, son numerosas: entre éstas tenemos a Khlebnikov, representante del movimiento futurista. El autor de este modo les rinde homenaje.

Darío Villanueva distingue en la novela histórica española de los años 1980 cuatro categorías (Holloway, 1999: 131). "La parte de Archimboldi" estaría encuadrada en la segunda: "La fabulación, es decir, la preeminencia de la aventura argumental, elaborada con un trasfondo histórico" (Holloway, 1999: 131). Las otras categorías son: la recreación testimonial de un tiempo pasado, la recreación del pasado como metáfora del presente y el uso del pasado como contexto de una creación retórica, fantástica o mítica.

\section{Introducción de personajes: vida pasada}

Otro recurso narrativo típicamente romántico es la introducción de un personaje en la trama sin haber dado noticias previas al lector de su identidad; a continuación, en el párrafo siguiente a la introducción del personaje, un narrador omnisciente en tercera persona cuenta su vida, remontándose a tiempos pasados, usando la técnica del racconto o analepsis ${ }^{2}$. De este modo, se rompe la secuencia cronológica de la historia. También, puede ocurrir que los mismos personajes narren su vida pasada, produciendo el mismo efecto en el lector, como ocurre en los ejemplos que exponemos a continuación:

Ejemplo 1: El escritor Efrain Ivanov.

El escritor Ivánov aparece por primera vez en la historia y, en el párrafo siguiente, se explica su vida pasada:

2 Alfonso Sánchez Rey (1991): "Llamamos analepsis a la evocación, fuera de lugar de un acontecimiento anterior al momento preciso de la historia en que se introduce tal acronía. Es decir, volver sobre un hecho anterior que se ha producido antes de lo que se está contando" (p. 353). 
Cuando Ivánov le decía que eso era imposible, que la muerte estaba junto al hombre desde tiempos inmemoriales, contestaba que de eso precisamente se trataba, justo de eso, incluso exclusivamente de eso, abolir la muerte, abolirla para siempre, sumergirnos todos hasta encontrar otra cosa. La abolición, la abolición, la abolición.

Ivanov era miembro del partido comunista desde 1902. En aquella época había intentado escribir cuentos a la manera de Tolstói, Chéjov, Gorki, es decir había intentado plagiarlos sin demasiado éxito, por lo que, tras una larga reflexión (toda una noche de verano), decidió astutamente escribir a la manera de Odoevski ${ }^{3}$ y Lazhéchnikov $^{4}$ (Bolaño, 2005: 888) [Notas del añadidas].

\section{Ejemplo 2: Nadja}

Dentro de la historia del escritor Efrain Ivanov se relata otra historia. Un nuevo personaje es introducido: "una muchacha que vestía un chaqueta de cuero" (Bolaño, 2005: 905). Esta muchacha expulsa a Ivanov del entierro de Gorki. Después de un punto y aparte, un narrador omnisciente - en tercera persona- cuenta la historia de Nadja, que hemos comentado más arriba: "Se llamaba Nadja Yurenieva y tenía diecinueve años. Esa misma noche hizo el amor con Ansky, después de que Ivánov consiguiera dormirse tras varios vasos de vodka (Bolaño, 2005: 906)".

El mismo procedimiento utiliza Patricio de la Escosura. Introduce a la sirvienta Manuela Fernández en el entorno de Laura, la protagonista de El Patriarca del Valle (1846-1847), y, luego, nos cuenta una larga historia -analepsis- donde se explica su vida anterior. El objetivo de este largo excurso es presentar la situación de pobreza y desprecio en la que caían las viudas de los sargentos liberales, durante los años posteriores a 1823 en el reinado de Fernando VII (Escosura, 1846: tomo I, 171-174):

Manuela Fernández, que así se llamaba, era natural de Madrid y sus barrios bajos, y tenía a la sazón treinta y cuatro o treinta y cinco años de edad (Escosura, 1846: tomo I, 172).

Pero Manuela [...] era de suyo [sic] virtuosa, y prefirió constantemente la miseria a la prostitución. Su pecho no era sin embargo de mármol: un elegante sargento segundo, escribiente de la mayoría de su regimiento, se prendó de la airosa manola, que tardó poco en confesarse vencida, si bien antes de rendir pabellón quiso absolutamente que interviniese en el asunto el cura de la parroquia (Escosura, 1846: tomo I, 172).

Ejemplo 3: Viejo dueño de la máquina de escribir

Aquí la historia del personaje viene narrada por el mismo personaje. Reiter va a alquilar una máquina de escribir y se cambia el nombre por el de Benno von Ar-

${ }^{3}$ Cuentista ruso (1803-1869). En su novela Año 4338 predice las conexiones por Internet. Citándolo Bolaño, rinde homenaje a los literatos menores.

${ }^{4}$ Novelista ruso (1792-1869). Autor menor de novelas históricas populares. 
chimboldi por miedo a ser encontrado por haber asesinado al nazi Stammer. El señor mayor que le alquila la máquina hace un largo excurso sobre distintos temas: sobre su padre que era escritor, sobre los poetas mayores y menores, sobre la vanidad de todo escritor y sobre cómo hay que hacer literatura basada en la realidad y no en los libros. También, este señor le cuenta a Reiter (ahora Benno von Archimboldi) cómo se encontró con un enterrador, que era escritor. Todas las narraciones de este personaje, del que no sabemos su nombre, constituyen una larga analepsis, que ocupa nueve páginas (Bolaño, 2005: 980-989). "Finalmente encontró a un viejo que poseía una vieja máquina de escribir francesa y que, aunque no se dedicaba a alquilarla, hacía una excepción con los escritores" (Bolaño, 2005: 980).

El punto de vista cambia; ahora es el mismo personaje, "un viejo", quien nos cuenta su vida:

-Pero lo dejé [el oficio de escribir]. Esta máquina me la regaló mi padre. Un padre cariñoso y culto que llegó a vivir hasta los noventa y tres años de edad. Un hombre básicamente bueno. Un hombre que creía, de más esta decirlo, en el progreso y por supuesto creía en la bondad intrínseca del ser humano. Yo también creo en la bondad intrínseca del ser humano, pero eso no significa nada. Un asesino, en el fondo, es bueno. Los alemanes eso lo sabemos bien (Bolaño, 2005: 982).

Ejemplo 4: Véase también: la historia de la señora Gottieb, sirvienta del editor Bubis, que lo ayuda a huir de la Alemania nazi (Bolaño, 2005: 1006).

Como hemos visto más arriba, existe una similitud formal en la utilización de este recurso por parte de Roberto Bolaño y Patricio de la Escosura. También, existe un objetivo común: concretar o hacer visible una situación histórica de unos personajes novelescos que están determinados por la Historia. Pero esto no quiere decir que ideológicamente exista parecido entre Escosura y Bolaño. Este último toma los lugares comunes de la novela de folletín romántica y los altera. Si Manuela Fernández era "honrada" y se casa con un sargento liberal, Nadja, por el contrario, la misma noche en que conoce a Ivánov hace el amor con él, sin apenas conocerlo. Bolaño utiliza irónicamente unos moldes populares. De este modo, consigue crear una literatura nueva, "de límites", que sorprende al lector y es lejana a lugares comunes o códigos establecidos; objetivos que son primordiales para él: "Trato de desarrollar una escritura pensada al máximo, que vaya sin ningún problema a algunos límites y, al mismo tiempo, que sea humorística en donde la atención y el sentido del humor vayan juntos (Acuña, 1998: 76) [Énfasis añadido].

\section{Presencia del autor}

La presencia del autor en la novela romántica ha sido estudiada por Romero Tobar; el autor aparece por sí mismo o bajo la apariencia de un narrador omnisciente 
que, por medio de excursos narrativos, ejerce una finalidad docente. Distingue tres tipos de excursos: en el primer tipo, el autor expone "la manifestación directa de sus intenciones", en el segundo, llamado excurso encubierto, el autor expone "largos parlamentos puestos en boca de los personajes presentados como modélicos" y en un tercer tipo, el autor divaga sobre temas variados (1976: 153-154).

El episodio, que comentamos a continuación, se encuadraría en los segundos excursos encubiertos, ya que el autor, Roberto Bolaño, expresa, en boca de un personaje, su angustia ante a la eminente muerte por su enfermedad hepática, y el modo de abordar la desgracia mediante la acción. El anciano, al igual que Roberto Bolaño, "se mueve al compás del engranaje"; uno entierra y otro escribe. Reiter va a alquilar una máquina de escribir a un anciano. Éste cuenta cómo encontró a un escritor alemán trabajando en la morgue al que le preguntó si su trabajo le hacía reflexionar sobre el destino humano. El anciano simboliza la situación personal de Roberto Bolaño, que escribe 2666 (2004) sabiendo que pronto morirá: "No tengo mucho tiempo, he de respirar, comer, beber, dormir. No tengo mucho tiempo, he de moverme al compás del engranaje. No tengo mucho tiempo, estoy viviendo. No tengo mucho tiempo, me estoy muriendo (Bolaño, 2005: 989) [Énfasis añadido]".

Una obsesión del autor es el olvido en que caen los escritores que no llegaron a escribir obras maestras. Esta idea es recurrente en sus declaraciones en los medios y en los distintos excursos de 2666 (2004). Al citar las obras del novelista alemán Döblin, vemos un homenaje a un autor que no llegó a ser todo lo conocido que debiera (Bolaño, 2005:1023). Bolaño está obsesionado por la fama y con los autores menores que no llegaron completamente a ella. Igualmente, más adelante, Archimboldi compara la luz de las estrellas con la luz de los libros; ambos fueron creados en el pasado pero sus efectos persisten (Bolaño, 2005: 1041).

\section{Narrador omnisciente}

En "La parte de Archimboldi" tenemos a un narrador omnisciente 'disfrazado', ya que el judío Ansky, autor del diario, ve los hechos y da su opinión, al modo del narrador decimonónico típico de las novelas populares. Este narrador es capaz de saber los sentimientos y móviles de su personaje. Así, se introduce en los sentimientos íntimos de Ivánov y nos asegura que éste sentía miedo al olvido y a no ser reconocido en el mundo de las letras -al igual que el mismo Roberto Bolaño:

¿A qué tenía miedo Ivánov?, se preguntaba Ansky en sus cuadernos. No al peligro físico, puesto que como antiguo bolchevique muchas veces estuvo próximo a la detención, la cárcel y la deportación, y aunque no se podía decir de él que fuera un tipo valiente, tampoco se podía afirmar, sin faltar a la verdad, que fuera una persona cobarde y sin agallas. El miedo de Ivánov era de índole literaria. Es decir, su miedo era el miedo que sufren la mayor parte de aquellos ciudadanos que un 
buen (o mal) día deciden convertir el ejercicio de las letras y, sobre todo, el ejercicio de la ficción en parte integrante de sus vidas. Miedo a ser malos. También, miedo a no ser reconocidos. Pero sobre todo miedo a ser malos. Miedo a que sus esfuerzos y afanes caigan en el olvido (Bolaño, 2005: 903) [Énfasis añadido].

Este narrador omnisciente -Ansky,- se atreve a juzgar a su personaje Ivanov; lo considera ridículo porque se compara con el Quijote.

Así que Ivánov se consideraba el Cervantes de la literatura fantástica. Veía nubes con forma de guillotina, veía nubes con forma de tiro en la nuca, pero en realidad sólo veía a sí mismo cabalgando junto a un Sancho misterioso y útil por las estepas de la gloria literaria (Bolaño, 2005: 904) [Énfasis añadido].

Pero, aunque técnicamente podemos hablar de un autor omnisciente, tanto en Roberto Bolaño como los autores románticos, conceptualmente su tratamiento es distinto; el narrador omnisciente de la novela romántica es seguro, lleva al lector por la senda moralmente adecuada y nunca lo deja a la deriva. Presenta los hechos sin toque de ironía. Así, por ejemplo, en el capítulo V de El Patriarca del Valle (1846-1847) de Escosura, "La belle espagnole", el narrador, lleno de entusiasmo, elogia a París por ser un lugar divertido para el viajero:

El aficionado a espectáculos, más de veinte teatros donde elegir entre la tragedia clásica de Corneille y de Racine, la comedia aristotélica de Moliere o la intriga de Merrivaux. Sobran espléndidos cafés, pasadizos soberbiamente iluminados, plazas y galerías donde el ocioso se divierte gratis, abundan las bibliotecas y véndense a poco precio los libros para que el amante del estudio satisfaga su pasión.

El extranjero es siempre bien recibido, los que no le entienden, le adivinan: y si es verdad que le sacan el dinero, también que goza cuando gasta (Escosura, 1846: Vol. I, 135) [Énfasis añadido].

Por el contrario, el narrador de "La parte de Archimboldi" presenta a sus personajes irónicamente; éstos son unos prototipos de los viajeros actuales que disfrutan unos lugares consagrados por tópicos, promovidos exclusivamente para captarlos. El lector implícito no puede dejar de esbozar una sonrisa ante las siguientes líneas:

Visitaron, como dos vagabundos, Venecia y Milán, y entre ambas ciudades se detuvieron en Verona y durmieron en la pensión donde durmió Shakespeare, y que ahora se llama Trattoria Shakespeare, y también fueron a la iglesia adonde solía ir Shakespeare a meditar o a jugar al ajedrez con el cura párroco, puesto que Shakespeare, al igual que ellos, no hablaba italiano, aunque para jugar al ajedrez no era necesario hablar italiano ni inglés ni alemán ni siguiera ruso (Bolaño, 2005: 1046) [Énfasis añadido]. 
Roberto Bolaño se aleja del "romanticismo cursi" y defiende esta línea humorística en la literatura, corriente que cultiva Nicanor Parra frente a Vicente Huidobro:

Los clásicos, por llamarlos de alguna manera, quiero decir los clásicos de nuestros países en desarrollo, sacrificaron el humor en aras de un romanticismo cursi y en aras de textos pedagógicos o, en algunos casos, de denuncia, que mal resisten el paso del tiempo y que si se mantienen es por un afán voluntarista de bibliófilo, no por el valor real, el peso real de esa literatura (Bolaño, 2004:224) [Énfasis añadido].

[...] Si releemos a Paz o si releemos a Huidobro advertiremos una ausencia de humor, una ausencia que a la postre resulta ser una cómoda máscara, la máscara pétrea. Menos mal que tenemos a Nicanor Parra. Menos mal que la tribu de Parra aún no se rinde (Bolaño, 2004: 225) [Énfasis añadido].

\section{Cambios de perspectiva en la narración}

En "La parte de Archimboldi" de Roberto Bolaño tenemos, algunas veces, un narrador que está por encima, sabe más y corrige las fuentes (2005: 904). El lector no reconoce si esos comentarios, que están entre paréntesis, son de Reiter, lector del diario del judío Ansky, o de un narrador en tercera persona omnisciente, exterior a la historia novelesca:

Por esas fechas Ansky trabajaba en un proyecto radiofónico que debía cubrir toda Europa y llegar también hasta el último rincón de Siberia. En 1930, decían los cuadernos, Trostki fue expulsado de la Unión Soviética (aunque en realidad fue expulsado en 1929, error atribuible a la transparencia informativa rusa) y el ánimo de Ansky empezaba a flaquear (.Bolaño, 2005: 904) [Énfasis añadido].

Este narrador omnisciente también resume y juzga el estado de sus fuentes, el diario: "Después vienen los apuntes, desordenados, sobre su huida. Hay amigos que conversan durante toda la noche sobre las ventajas e inconvenientes del suicidio" (Bolaño, 2005: 918) [Énfasis añadido].

Por lo tanto, existe una confusión sobre quién es el narrador: Reiter, que hace el papel del típico editor o recopilador de papeles encontrados, o un narrador exterior a la historia en tercera persona. A veces, parece ser un narrador omnisciente desde una perspectiva exterior a la historia, que narra los hechos desde fuera y observa cómo Reiter reflexiona ante los cuadernos de Ansky. Así nos dice:

Quedaba por dilucidar el escondite para una sola persona en el interior de la chimenea. ¿Quién lo hizo? ¿Quién se escondió allí?

Tras mucho cavilar, Reiter decidió que el constructor había sido Ansky (Bolaño, 2005: 921) [Énfasis añadido]. 
Esta confusión de la voz narrativa en 2666 (2004) ha sido considerada como un pretendido juego del autor:

De lectura colosal, 2666 es un proyecto narrativo que presenta, además del misterio del título, a un narrador sospechosamente omnisciente: ¿de quién es la voz? A veces, según el personaje sobre cuyo hombro se encuentre, adquiere un falso acento castizo, pero de inmediato cambia, es sólo un juego del autor (Cane, 2004) [Énfasis añadido].

\section{Anticipación o prolepsis}

La prolepsis es una anticipación en el discurso de unos hechos que ocurrirán posteriormente en la historia (Reis; M. Lopes, 2002:212). Típico del narrador omnisciente de la novela decimonónica es dar pistas al lector: "El narrador se adelanta a contar los acontecimientos antes de que ocurran. Avanza, a grandes rasgos, los hechos que tendrán lugar más tarde" (Castro; Montejo, 1990:70). Lo mismo ocurre en "De la parte de Archimboldi", el narrador comunica una desgracia venidera, la muerte de la novia de Ingeborg: "Por aquellos días Ingeborg y Archimboldi, como si presintieran algo, no paraban de hacer el amor (Bolaño, 2005:1036)". Un narrador en tercera persona omnisciente nos dice lo que imaginan sus personajes. Esto crea una sensación vaga y misteriosa en el lector implícito porque estima que la muerte de Ingeborg está cerca. También, cuando Ingeborg desaparece, Archimboldi la busca desesperadamente e imagina que le ocurren desgracias: "Imaginó a Ingeborg caminando sin fijarse en nada. La vio acercarse a uno de los barrancos. Dar un traspié. Caer" (Bolaño, 2005: 1040).

Pero, una vez más, la ironía y el uso opuesto de los códigos aparecen en la obra y las desgracias anunciadas no ocurren; Ingeborg se recupera de su enfermedad y, más tarde, no se cae a ningún barranco. Bolaño, burlonamente, busca provocar en el lector sorpresa y una sonrisa.

\section{Simbología}

En "La parte de Archimboldi" podemos distinguir tres tipos de simbología. Los dos primeros casos, que veremos a continuación, existen paralelamente en la novela popular; en el primero, los personajes actúan como símbolos de un grupo y son representativos de una colectividad que está determinada por su contexto histórico. Los personajes interesan en la medida en que son representativos o arquetipos de una clase social. Un ejemplo de este tipo lo tenemos cuando Ingeborg, al ver a Archimboldi escribir a máquina, evoca a la señora Dorothea. Ésta puede ser una de las miles de secretarias que mecanografiaban en las oficinas del régimen nazi en Berlín, 
colocadas en ordenadas filas y con el retrato de Hitler colgado en la pared. Dorothea interesa solamente porque representa a una clase social (Bolaño, 2005:1032-1034). Este tipo de simbología también aparece en la novela popular romántica. En el ejemplo comentado anteriormente de El patriarca del valle (1846-1847) de Patricio de la Escosura, Manuela Fernández es elegida para manifestar la penosa situación en que se encontraban las viudas de los soldados liberales. Tanto la señora Dorotea como Manuela Fernández no aparecerán posteriormente en la trama novelesca, su única función ha sido la de ejemplificar puntualmente una situación colectiva.

El segundo tipo de simbología se asemeja a la tendencia romántica de utilizar nombres simbólicos que dan pistas de la personalidad del personaje; así Laura, nombre de la heroína de El Patriarca de Valle (1846-1847), significa coronada de laurel o victoriosa; Don Ángel es perverso y todo lo contrario a un ángel y, también, Leoncio, es celoso como un león respecto a Laura. Del mismo modo Roberto Bolaño en "De la parte de Archimboldi" en 2666 (2004) utiliza este mismo recurso pero con distintos matices; Reiter es un soldado alemán aficionado de niño a las algas -a los seis años ya había robado un libro sobre este tema (Bolaño, 2005: 799), y a los ocho años es salvado por un turista que, en un principio, lo confundió con un alga (Bolaño, 2005: 805)-. Cuando Reiter teme ser descubierto por el asesinato del asesino nazi Stammer se cambia de nombre por el de Archimboldi; existe aquí una simbología, aunque más rebuscada y sofisticada, ya que el pintor Archimboldo en sus pinturas funde lo vegetal con lo humano, al modo de Reiter en su persona. Igualmente, la elección de ese pintor menor supone un homenaje a los autores menores, tema recurrente, como hemos visto, en el autor en "De la parte de Archimboldi":

Me dirá usted que la literatura no consiste únicamente en obras maestras sino que está poblada de obras, así llamadas, menores. Yo también creía eso. La literatura es un vasto bosque y las obras maestras son los lagos, los árboles inmensos o extrañísimos, las elocuentes flores preciosas o las escondidas grutas, pero un bosque también está compuesto por árboles comunes y corrientes, por yerbazales [sic], por charcos, por plantas parásitas, por hongos y por florecillas silvestres (Bolaño, 2005: 982) [Énfasis añadido].

En un tercer caso, podríamos hablar de una simbología interna o de una intertextualidad entre los distintos capítulos de 2666 (2004) basados en un tema común: los asesinatos de mujeres. El mal, plasmado en la crueldad contra las mujeres, está simbolizado en la historia del campesino Lube que mató a su esposa. Las palabras de Ingeborg al campesino -"hay mucha gente que mata, sobre todo a sus mujeres, y nunca va a parar a la cárcel (Bolaño, 2005: 1037)"- recuerdan al lector los asesinatos de México de "La parte de los crímenes" (Bolaño, 2005: 441). La historia particular simboliza un mal general que es común en todos los lugares, "que dista mucho ser un fenómeno local o nacional para erigirse más bien en un perturbador símbolo 
de la modernidad, de cómo y a qué precio opera la sociedad en el capitalismo tardío" (Galdo, 2005: 27).

Otra simbología o intertextualidad externa ha sido referida por autores como Ignacio Rodríguez de Arce (2009). Este último ve en la crucifixión del general Entrescu en 2666 (2005) una parodia de la muerte de los tiranos en la cruz, como ocurre en El fiscal (1993) de Augusto Roa Bastos. En esta novela el mariscal y dictador paraguayo Solano López, vencido por las tropas brasileñas del emperador don Pedro es crucificado por sus mismos hombres, al igual que Entrescu.

\section{Conclusión}

En "De la parte de Archibomdi", quinto capítulo de 2666 (2005) de Roberto Bolaño, observamos un gran parecido con la novela popular romántica de la segunda mitad del siglo XIX. Como hemos analizado, existen similitudes formales: la complejidad argumental, la cantidad de historias -enlazadas unas con otras, a veces, levemente- y el gran número de personajes -desdibujados y con ninguna relevancia en la historia novelesca principal-. Por lo que se refiere a la modalidad narrativa, el "relato de acontecimientos", al igual típico de la novela romántica, hace que éstos se presenten a los lectores como sucesos distantes y difíciles de leer por su cantidad y densidad.

También, existen algunas similitudes en los modos narrativos; Roberto Bolaño utiliza fundamentalmente un narrador omnisciente en tercera persona para su narración. Pero, aunque formalmente puedan establecerse similitudes, el narrador de "La parte de Archimboldi" es conceptualmente distinto al narrador firme, que moralmente instruye, de la novela romántica. El narrador omnisciente que presenta Bolaño ironiza lo que cuenta, poniendo así en duda los posibles valores que se deducirían de la situación narrada.

Igualmente, Roberto Bolaño altera los códigos narrativos tradicionales y se sirve de los tópicos usados en las novelas románticas populares para presentarlos al revés; ahora la protagonista ya "no es honrada" y los lugares que visitan unos enamorados no son idílicos, sino tan vulgares como los que frecuenta cualquier viajero. Las anticipaciones o analepsis anuncian desgracias pero, éstas no llegan a ocurrir; el autor se ríe del lector, juega con él, utilizando el bagaje cultural de ambos intertextualidad-. El valor simbólico que los autores románticos dan a sus personajes por medio de sus nombres adquiere en 2666 (2005) una dimensión más profunda; el nombre de Archimboldi no sólo muestra el modo de ser del personaje -su amor por el mundo vegetal-, sino que representa un homenaje a autores menores como el pintor milanes Archimboldo (1527-1593). Sus personajes, al igual que en la novela popular romántica, son símbolos de unas personas y de unos comportamientos colectivos conocidos por la sociedad. Son estereotipos: no evolucionan ni cambian como personajes en el tiempo novelesco. Su factor sorpresa viene dado 
exclusivamente por su inclinación al mal, pero, una vez que el lector se insensibiliza ante la perversidad más absoluta de éstos, la sensación de novedad desaparece.

Podemos pues concluir que "De la parte de Archimboldi" de Roberto Bolaño, capítulo extenso de 2666 (2004), es un ejemplo posmoderno de la unión de elementos cultos y populares donde los elementos folletinescos, utilizados de un modo distinto, se enlazan con una tradición española novelesca de corte realista e histórico que nace en la primera mitad del siglo XIX y adquiere elementos folletinescos, por influencia francesa, en la segunda mitad del siglo XIX.

\section{Apéndice}

\section{Introducción a la sinopsis}

La empresa de resumir 2666 (2004) es tan imposible como lo es sintetizar las novelas de folletín de la segunda mitad del siglo XIX. Muchos críticos se han rendido ante la tarea. La dificultad estriba en que, como dice Ana María Moix, "2666 es una novela de novelas" (2004). Del mismo modo, otros autores y autoras, como por ejemplo, $\mathrm{M}^{\mathrm{a}}$ Ángeles Donoso expresan esta imposibilidad:

Cualquier reseña sobre 2666 resulta insuficiente. Esta novela de más de mil páginas se escapa a cualquier tipo de definición, de abstracción, de resumen. Roberto Bolaño no nos entrega aquí una historia, sino muchas, demasiadas. No hay una interpretación o una visión de la realidad, sino opiniones encontradas, versiones disímiles (2006).

A pesar de las opiniones anteriores, intentaremos, a continuación, hacer un resumen del argumento.

\section{Sinopsis}

El alemán Hans Reiner nace en 2920 en una aldea alemana allí vive con sus padres y su única hermana, Lotte, más pequeña que él. A Reiner le gusta nadar y es aficionado a las algas. El año que Hitler sube al poder, 1933, Reiter abandona la escuela porque el director le dice a su madre que no está capacitado para estudiar. Después de ser despedido de muchos trabajos, va a ayudar a su madre a arreglar la casa de campo de un barón prusiano. Esta casa era frecuentada por su sobrino Hugo Halder-y, otras veces, por la hija del barón -la baronesa Von Zumpe-. Reiner se hace amigo de Hugo Halder porque sabe guardar el secreto de que éste roba a su tío objetos de la casa de campo para pagar sus deudas de juego. Por mediación de Halder, Reiner lee Parsifal de Wolfram y descubre que este autor está "liberado de la carga de los latines", (Bolaño, 2005: 822). En 1936 el barón cierra la casa de campo y Reiter trabaja construyendo las carreteras del Reich, pero no le gusta y lo deja. En Berlín, Halder le consigue un trabajo como ayudante en una papelería; 
vive con un vigilante nocturno llamado Füchler, que estaba enfermo. Cuando éste muere, Reiter hereda su puesto, en el que trabaja de noche. Por el día sale con Halder y con un japonés, Nisamata; juntos frecuentan los cabarets berlineses y terminan sus juergas en casa de Grete, amiga de Halder. En 1939 Hans Reiter es llamado a filas y destinado a treinta kilómetros de la frontera polaca. Ante de irse, sale con sus amigos y conoce a Anita, una prostituta, con la que pierde la virginidad. Al empezar la segunda guerra mundial en septiembre, la división de Reiter cruza la frontera polaca. Lucha contra los polacos en Kutno. Un compañero de armas, Gustav, se vuelve loco por las atrocidades que vive en la guerra. Después de cercar a soldados franceses en Nancy, su división fue acuartelada en Normandía. Allí Rieter sale a nadar y tiene tentaciones de dejar el ejército y esconderse en la zona. Luego, fueron destinados a Rumania y su batallón se instala en los Cárpatos. La tropa llega a un castillo donde, más tarde, llega también el general rumano Entrescu, acompañado del joven erudito capitán Pablo Propescu y de la baronesa Von Zumpe. Reiter junto con otro soldado, Wilke, espía las relaciones amorosas que tienen la baronesa y Entrescu. Más tarde, Reiter consigue dos permisos y visita a sus padres; durante este tiempo está con su hermana Lotte y, también, va a Berlín para buscar a Hugo Halder. En el edificio donde este debería estar, conoce a Ingeborg, su futura novia; mantiene un diálogo sobre los aztecas -el autor deja patente su extenso conocimiento sobre ese pueblo en un largo excurso-.

Por medio de Ingeborg se entera de que Hugo Halder está en París. Los rumanos, junto con los alemanes, atacan en 1941 a la Unión Soviética. Reiter recibe la cruz de hierro en un hospital de campaña; no puede hablar porque una bala le ha atravesado la garganta. Es enviado a Kostekino cerca del río Dniéper (aldea inexistente, quizás ideada por el autor en honor de Maximiliano Kosteki, un militante argentino que peleó por los derechos del trabajador y de las clases populares). En Kostekino, en una casa abandonada por los judíos, en el hueco de la chimenea, encuentra el diario del judío alemán Boris Aramvich Ansky.

La historia de Ansky se cuenta detalladamente: a los catorce años el judío Ansky se alista en el ejército rojo y, después de estar en diversos lugares, se instala en Moscú. Ansky cree en la revolución y conoce al escritor Efraim Ivánov (narración de la historia de Ivanov; de su éxito y postergación por el régimen comunista. Historia de la rusa revolucionaria Nadja y cómo hace el amor con Ansky). Ansky en Moscú se siente perseguido y nombra a las familias que lo acogen por medio de números. Se describe el gusto de Ansky por la pintura del italiano Giuseppe Archimboldi y por Corbert, del que se hace un largo inciso sobre su vida revolucionaria en la comuna de Paris.

Reiter vuelve a Kostekino. A los pocos meses de llegar, su padre su muere. "Por aquellos días Hitler invade Polonia y empieza la Segunda Guerra Mundial" (Bolaño, 2005:920). Reiter se pregunta quién hizo el escondite donde estaba el diario de Ansky e imagina cómo la madre, antes de ser conducida por los alemanes junto con otras familias judías al exterminio, escondería el diario. Reiter vive en la casa del 
judío Ansky y se figura la vida de éste y de sus padres; tiene pesadillas en las que él se ve asesinando al judío Ansky.

En 1942 Reiter se recupera de la herida en la garganta y recobra la voz. Vuelve con su división, siempre con el diario de Ansky bajo la casaca, y viaja con sus compañeros a Crimea y al Cáucaso, además de otros países. En el verano de 1943, los rusos atacan a la división de Reiter, y ésta retrocede. En esta retirada sólo quedan unos soldados que parecen locos. Él huye sólo y se va a Kostekino. En la aldea quedan únicamente unos viejos, porque los alemanes habían evacuado a los ucranianos jóvenes que tenían trabajando allí. Después de pasar unos días en la aldea, decide abandonar Kostekino y dejar el diario de Ansky en el lugar donde lo encontró, la chimenea.

Se une a un batallón alemán. En 1944, divisa con sus prismáticos a unos soldados rumanos; se acerca junto con su batallón, y observa que el batallón rumano, antes de desertar, ha colgado en una cruz a su general, Entrescu. Reiter pregunta por el capitán que siempre lo acompañaba, Pablo Propescu, y los soldados le responden que éste ya debe estar huido en Bucarest.

Finalmente, en 1945 Reiter se rinde a los americanos que lo internan en el campo de concentración de Ansbach. Allí conoce a Zeller que, en realidad, se llama Leo Stammer. Éste le confiesa que es responsable de haber matado a centenares de judíos en un pueblo polaco; las autoridades alemanas le mandaban trenes llenos de judíos griegos o serbios y él tenía que deshacerse de ellos; se le ocurrió emborrachar a niños polacos para que dispararan a los judíos. Un día Stammer aparece muerto en el campo de concentración; lo ha matado Reiter (Bolaño, 2005:960).

Reiter, asustado por haber asesinado a Stammer, abandona el campo y se va a Colonia. Allí vive con Otto, periodista, y con Gustav, que había sido conductor de los tanques alemanes, panzers. Reiter se coloca como camarero. Cuando estaba de servicio, le visita Ingeborg Bauer. Al principio, no la reconoce pero, luego, se acuerda de ella. Se van a vivir juntos. Reiter la cuidada porque ella está muy enferma (Bolaño, 2005:967). Entre ellos hablan de libros (el autor nos expone "su teoría literaria" Bolaño, 2005: 968). Ingeborg mira a Reiter (tenemos la primera descripción del personaje) y lo ve con ojos azules y pelo rubio. Reiter le confiesa a Ingeborg que había matado a Stammer y le cuenta cómo huyó del campo de concentración y cómo una vieja adivina le regaló una chaqueta negra (largas digresiones sobre las chaquetas de cuero negro y conjeturas sobre a quién había pertenecido la que la vieja adivina había regalado a Reiter, Bolaño, 2005: 973-976). Reiter cuida a la enferma Ingeborg (patética descripción de Reiter haciendo el amor con una moribunda a quien la enfermedad le había aumentado el apetito sexual). Reiter practica el coito anal con Ingeborg delante de sus hermanas y su madre ("¿Pero qué le hacía él a Ingeborg sino amarla?", Bolaño, 2005: 979).

Después de la visita de su madre y sus hermanas, Ingeborg se recupera: empieza a trabajar de costurera con la señora Raab en Colonia (Bolaño, 2005:980). Mientras, Reiter termina su primera novela, Lüdicke, y busca a alguien que le alquile una 
máquina de escribir. Se cambia el nombre por el de Benn von Archimboldi, por miedo a ser perseguido por haber matado a Stammer. Se narra la historia del anciano que le alquila la máquina (Bolaño, 2005: 980-989); se toca el tema de los escritores menores (Bolaño, 2005: 983) y el de la vanidad de los escritores (Bolaño, 2005: 984).

Archimboldi (antes Reiter) encuentra en Colonia a los dos vagabundos, Otto y Gustav, con los que había vivido antes de irse a la buhardilla con su novia. Otto, el periodista, no puede encontrar trabajo en ningún periódico, debido a su pasado nazi, ésta situación le hace pensar en el suicidio (Bolaño, 2005:990). El tanguista nazi, Gustav, ahora se ha hecho comunista y repara motores.

Archimboldi manda su novela a dos editoriales. Después de muchas vicisitudes, Bubis, un editor de Hamburgo, acepta editarle Lüdicke. Se narra la historia de la editorial de Bubis y de la señora Marianne Gottlieb, empleada que ayudó a huir de los nazis al señor Bubis. Se expone el concepto de patria de Bubis -que es reflejo del concepto del autor ${ }^{5}$ - (Bolaño, 2005: 1008). La baronesa Von Zumpe (hija del barón Von Zumpe y dueño de la casa donde su madre limpiaba, cuando Reiter era pequeño) es la mujer de Bubis (Bolaño, 2005: 1015). Archimboldi se acuesta con la baronesa y le cuenta cómo murió crucificado el general Entrescu, que había sido amante de ésta (Bolaño, 2005: 1019). Se narra detalladamente la aceptación de las obras de Archimboldi por parte de los lectores (Bolaño, 2005: 1021-1035). Ingeborg enferma y Archimboldi la traslada a Kempten, al sur de Alemania, porque piensa que su clima seco la mejoraría. Allí son felices; Archimboldi escribe. El ruido de la máquina, le sirve a Ingerborg para evocar las oficinas del régimen de Hitler y, concretamente, la mecanógrafa Dorothea, a la que visitaba con su padre (Bolaño, 2005: 1032). Cansados de esta ciudad, se van a una aldea cercana. Allí viven en casa de un campesino, Fritz Leube, que había arrojado a su mujer por un barranco (Bolaño, 2005: 1036).

Finalmente, Reiter va a México a ayudar a sobrino, Klaus, hijo de Lotte (historia pormenorizada de Lotte: sus matrimonios y negocios). Éste estaba en una cárcel de México acusado de matar a mujeres.

\section{BIBLIOGRAFÍA}

ACUÑA, Marcela.

1998 "Una visita ilustre", Ercilla, 30 de noviembre, n 3.099, p. 76.

5 "Bolaño [...] matizaba: 'Muchas pueden ser las patrias pero uno solo el pasaporte, y este pasaporte, evidentemente, es la calidad de la escritura" (texto leído en homenaje a Roberto Bolaño en la feria del libro chilena, en Herralde, 2005: 29). 
BOLAÑO, Roberto.

2005 2666. Barcelona: Anagrama.

2008 "Humor en el rellano", en Entre paréntesis. Barcelona: Anagrama, pp. 224-225, $3^{\mathrm{a}}$ ed.

2009 "Los mitos de cthulhu", en El gaucho insufrible. Barcelona: Anagrama, pp. 159-177, $2^{\mathrm{a}}$ ed.

BROWN, Reginald F.

1953 La novela española 1700-1850. Madrid: Dirección General de Archivos y Bibliotecas.

CANE, Miguel.

2004 “Misterios gozosos y dolorosos: 2666”. Milenio diario, México, 5 de diciembre. Disponible en:

http://www.sololiteratura.com/bol/bolmiguelcane.htm

CASTRO, Isabel de y Lucía MONTEJO.

1990 Tendencias y procedimiento de la novela española actual (19751988). Madrid: UNED.

DoNoso, Ángeles.

2006 "2666: violencia y literatura en las fronteras de la realidad latinoamericana", en Proyecto patrimonio. Página chilena al servicio de la cultura: www.letras.s5.com. Dirigida por Luis Martínez. Disponible en: http://www.bifurcaciones.cl/005/2666.htm

ESCOSURA, Patricio de.

1846-1847 El patriarca del valle (II tomos) Madrid: Mellado.

FRAGERO GUERRA, Carmen.

1989 Romanticismo y novela: Estudio del patriarca del valle. (Microfichas). Córdoba: Servicio de Publicaciones de la Universidad de Córdoba.

1997 "La novela romántica: aportación del cordobés Fulgencio Benítez Torres (1812-1844)", en Diego Martínez Torrón (ed.). Los románticos y Andalucía. Córdoba: Servicio de Publicaciones de la Universidad de Córdoba, pp. 149-175.

2000 "Una novela realista dentro del Romanticismo: Los cortesanos y la revolución (1838-1839) de Eugenio de Tapia”, en Diego Martínez Torón (ed.). Estudios de literatura romántica española. Córdoba: Servicio de Publicaciones de la Universidad de Córdoba, pp. 103-116.

GALDO, Juan Carlos.

2005 "Fronteras del mal/genealogías del horror: 2666 de Roberto Bolaño". Hipertexto (2), Summer, 23-34. Disponible en: http://www.utpa.edu/dept/modlang/hipertexto/hiper2indice.htm

HERRALDE, Jorge.

2005 Para Roberto Bolaño. Barcelona: Acantilado. 
Holloway, Vance R.

1999 El posmodernismo y otras tendencias de la novela española (19671995). Madrid: Fundamentos.

MoIX, Ana María.

2004 "Un torrente llamado Bolaño", El País.com. Babelia, 23 de Octubre. Disponible en:

http:/www.elpais.com/articulo/semana/torrente/llamado/Bolano/elp

NAVAJAS, Gonzalo. epuculbab/20041023elpbabese $13 /$ Tes

1996 Más allá de la posmodernidad. Barcelona: EUB.

PASTENE LABRÍn, Federico.

2004 "La era del acceso y de la novela popular: Una lectura de Hija de la Fortuna de Isabel Allende", Theoría, vol.13, Chile: Universidad del Bío-Bío, pp.111-120. Disponible en:

http://redalyc.uaemex.mx/pdf/299/29901311.pdf

REIS, Carlos y Ana Cristina M. LOPES.

2002 Diccionario de narratología (2 ${ }^{\mathrm{a}}$ ed.).Salamanca: Almar, $2^{\mathrm{a}}$ ed.

RODRÍGUEZ DE ARCE, Ignacio.

2009 "El tirano en la cruz: un modelo aplicativo de lectura conjuntiva", Espéculo: Revista de estudios literarios, $\mathrm{n}^{\circ}$ 43, Universidad Complutense de Madrid. Disponible en:

http://www.ucm.es/info/especulo/numero43/tiranoc.html

ROMERO TOBAR, Leonardo.

1976 La novela popular española del siglo XIX. Madrid: Ariel.

SÁNCHEZ REY, Alfonso.

1991 El lenguaje literario de la nueva novela hispánica. Madrid: MAPFRE. 